\title{
Periodic Fever accompanied by Aphthous stomatitis, Pharyngitis, and cervical Adenitis syndrome (PFAPA syndrome) in adults S Padeh*, N Stoffman and Y Berkun
}

\author{
Address: Edmond and Lily Safra Children's Hospital, Sheba Medical Center, Tel Hashomer, Israel \\ * Corresponding author
}

\author{
from $15^{\text {th }}$ Paediatric Rheumatology European Society (PreS) Congress \\ London, UK. 14-17 September 2008 \\ Published: 15 September 2008 \\ Pediatric Rheumatology 2008, 6(Suppl I):PI83 doi:I0.II86/I546-0096-6-SI-PI83
}

This abstract is available from: http://www.ped-rheum.com/content/6/SI/PI83

(c) 2008 Padeh et al; licensee BioMed Central Ltd.

\section{Background}

The syndrome of periodic fever characterized by abrupt onset of fever, malaise, aphthous stomatitis, tonsillitis, pharyngitis and cervical adenopathy (PFAPA syndrome) has been described only in pediatric patients. It usually begins before the age of 5 and in most cases resolves spontaneously before the age of 10 years. The aim of this report is to describe a series of adults with PFAPA syndrome.

\section{Methods}

A 6 years retrospective descriptive study included all newly diagnosed incident adult cases aged 18 years and over referred to our center with symptomatology suggestive of PFAPA syndrome. Patients' medical records were reviewed for past history of the disease, demographic characteristics, symptoms and signs, course of the disease, laboratory findings and outcome following corticosteroid therapy. The comparison group included our pediatric cohort children ( $\mathrm{N}=320$, age between 0.5 to 18 years) followed-up since 14 years (1994).

\section{Results}

Fifteen adult patients were diagnosed with PFAPA syndrome. Episodes of fever occurred at $4.6 \pm 1$.3-week intervals, beginning at the age of $20.9 \pm 7.5$ years. All patients had monthly attacks at the peak of the disease, with attacks recurring between 4-8 weeks intervals over the years. Between episodes, all patients were apparently healthy, without any accompanying diseases. Attacks were aborted by a single $60 \mathrm{mg}$ of oral prednisone in all patients.

\section{Conclusion}

This study reports the presence of PFAPA syndrome in adult patients. Although rare, an increased awareness by both patients and family physicians of the clinical syndrome has resulted in more frequent diagnosis in adult patients. 